\author{
SERIES 'CLINICAL PHYSIOLOGY IN RESPIRATORY INTENSIVE CARE' \\ Edited by A. Rossi and C. Roussos \\ Number 12 in this Series
}

\title{
Heart-lung interactions: applications in the critically ill
}

\author{
H.E. Fessler
}

\begin{abstract}
Heart-lung interactions: applications in the critically ill. H.E. Fessler. CERS Journals Ltd 1997.

ABSTRACT: Since the circulatory and pulmonary systems are both driven by pressure and share space in the thorax, it is inevitable that they interact. These mechanical interactions, whilst relatively few in number, are protean in their manifestations.

The circulatory system of the critically ill is often particularly susceptible to interference from respiration. Compensatory reserve is limited, ventilatory effort increased, and many critical care respiratory interventions place strain on the circulation, not seen in health.

This review will examine the basic physiological mechanisms through which the pulmonary and circulatory systems interact. These mechanisms will then be applied to a variety of weaning, positive end-expiratory pressure (PEEP), and cardiopulmonary resuscitation techniques. It is hoped that this will provide the tools to understand clinical observations which would otherwise appear inexplicable. Eur Respir J., 1997; 10: 226-237.
\end{abstract}

Dept of Medicine, Division of Pulmonary and Critical Care Medicine, Johns Hopkins Medical Institutions, Baltimore, Maryland, USA.

Correspondence: H.E. Fessler

Pulmonary and Critical Care Medicine

Johns Hopkins Asthma and Allergy Center Baltimore, Maryland

USA 21224

Keywords: Artificial respiration, cardiopulmonary, critical care, positive endexpiratory pressure

Received: October 151996

Accepted for publication November 71996

Dr. Fessler is supported by a Grant-in-Aid from the American Heart Association.

Heart-lung interactions occur with every breath. Their effects may be subtle during normal health, but can be profound during critical illness. Respiratory disease exaggerates the normal stresses of breathing, and circulatory disease compromises the response to these stresses. Common signs of circulatory dysfunction, such as pulsus paradoxus and Kussmaul's sign, result from mechanical effects of respiration upon the circulation. Common intensive respiratory interventions, such as positive pressure ventilation and positive end-expiratory pressure (PEEP), have substantial effects on systemic blood flow. Common diseases, such as heart failure, alter the circulatory effects of these interventions. The complexity of heart-lung interactions, coupled with the complexity of critical illness, creates a topic which resists facile digestion and organization.

This paper will first review basic principles of circulatory function. The mechanical effects of respiration will be reduced to a small group of stresses. These stresses contribute to different conditions in variable proportion, and the mechanical response may be further modified by reflex or humoral factors. The emphasis will be on mechanical aspects of heart-lung interaction. A comprehensive review of the neural and humoral effects of ventilation is beyond the scope of this article, and the interested reader is directed elsewhere [1].

Next, the basic stresses will be used to explain some signs of critical illness and the effects of PEEP, weaning, and cardiopulmonary resuscitation (CPR). Whilst emphasis will be placed on recent insights, respect will be paid to the observations of physicians and physiologists dating back centuries. Contradictory data, controversy, and the limits of our understanding will be stressed. It is hoped that this approach will stimulate the interest of a new generation of scientific observers and experimenters.

\section{Basic principles}

\section{Normal circulatory function}

The effects of respiration will be illustrated using a simplified mechanical model of the systemic circulation (fig. 1). From the heart, blood is pumped through an arterial resistance into a compliance, indicated by the reservoir, which represents the lumped compliance of the systemic circulation. The pressure at the outflow end of this reservoir is termed mean systemic pressure $(\bar{P}$ syst $) . \bar{P}_{\text {syst }}$ is a crucial determinant of steady-state systemic flow, as recognized by WeBER [2] and later by Starling $[3,4] . \bar{P}_{\text {syst }}$ is determined by the elastic properties of the systemic vessels and the volume of blood they contain. It is the average of the pressures throughout the systemic circulation, with the contribution of each vascular segment weighted by its fraction of the total compliance of the systemic circulation. Because most of the compliance resides in the low pressure veins, $\bar{P}_{\text {syst }}$ is much closer to central venous than to arterial pressure [5].

Flow from the heart to the reservoir requires cardiac contraction, but venous return occurs passively, driven by the pressure gradient between $\bar{P}_{\text {syst }}$ and right atrial pressure $\left(P\right.$ ra). At constant $\bar{P}_{\text {syst, }}$, venous return increases as $P$ ra decreases. The relationship between venous flow and its driving pressure gradient is the resistance to venous return. As was shown by GUYTON and co-workers 


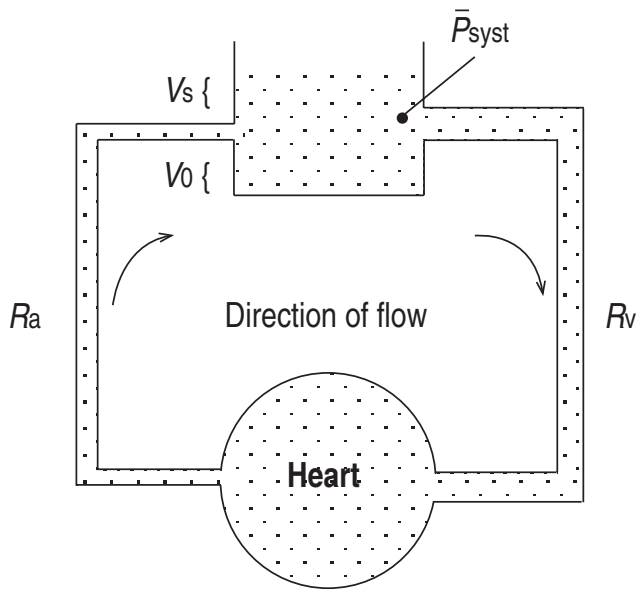

Fig. 1. - Simplified model of the systemic circulation. The heart pumps blood clockwise through an arterial resistance $(R$ a $)$ into a reservoir. Pressure at the outflow of the reservoir is mean systemic pressure $\left(\bar{P}_{\text {syst }}\right)$, determined by the chamber compliance (here, its diameter), and the stressed volume $\left(V_{\mathrm{s}}\right)$. Total volume is the sum of $V_{\mathrm{s}}$ and the unstressed volume $\left(V_{0}\right)$. Venous return occurs passively, driven through the venous resistance $(R \mathrm{v})$ by the pressure difference between $\bar{P}_{\text {syst }}$ and the right atrium.

$[5,6]$, however, venous return cannot increase indefinitely. When Pra falls somewhat below atmospheric pressure, venous return becomes maximal and fails to increase despite further lowering of Pra [6]. This "flow-limitation" is governed by the same mechanisms that produce flow limitation in the airways or other collapsible tubes $[7,8]$. Since $P$ ra is normally near zero, it is apparent that further reductions do little to increase venous return (and hence cardiac output). The large increases in cardiac output seen with exercise, fever or sepsis, must, therefore, also involve changes in $\bar{P}_{\text {syst }}$ or in the resistance to venous return [9].

Changes in $\bar{P}$ syst can occur in one of three ways. Either the total volume in the reservoir can change, the compliance (diameter) of the reservoir may change, or volume may be shifted from the portion of the reservoir below its outflow (the "unstressed volume", the volume at an outflow pressure of zero) into the segment above the outflow (the "stressed" volume). In the acute response to catecholamines, changes in unstressed volume appear to predominate [10-13]. Teleologically, this is sensible. In the setting of haemorrhage, restoration of $\bar{P}_{\text {syst }}$ by reducing compliance would leave $\bar{P}_{\text {syst }}$ increasingly vulnerable to further volume loss.

The pulmonary circulation (not shown in figure 1) functions identically to the systemic circulation. In this case, the right ventricle pumps blood into the pulmonary reservoir, from which it drains passively through a pulmonary venous resistance to the left atrium. Both systemic and pulmonary venous resistances are normally so low that the entire cardiac output is returned to the respective atrium by only $5-10 \mathrm{mmHg}$ pressure.

A slightly more complicated model of the circulation is shown in figure 2. The heart and lungs are surrounded by pleural pressure $(P \mathrm{pl})$, and the heart enclosed by a pericardium. Different portions of the pulmonary vessels are subjected to alveolar pressure $(P A)$ (the "alveolar" vessels) or $P$ pl (the "extra-alveolar" vessels) [14]. The systemic circulation is divided into abdominal beds, surrounded by abdominal pressure $(P \mathrm{ab})$, and nonabdominal beds. In this model, the resistance to venous return is an average of the individual venous resistance of the two beds, weighted by the distribution of flow through them and their compliance. Total venous resistance can be altered by changing the calibre of the veins or by changing the distribution of flow between parallel beds. Since the distribution of flow is determined in part by the resistance to inflow in each bed, this creates the seemingly paradoxical system in which venous resistance is determined by arterial resistance [15].

Also added to this model is a system of reflexes, which can influence resistances, compliances, and pump function. Complex as this model appears, it remains grossly simplistic. It omits many key features of the circulation, such as the critical closing pressures believed to exist in many systemic vascular beds. Nevertheless, this model contains the minimal essential elements for consideration of heart-lung interactions.

\section{Stresses upon the circulation}

Within the framework shown in figure 2, the mechanical stresses caused by respiration or respiratory manoeuvres can be resolved into four: stress on the surface of the heart; stress on intrapulmonary vessels; stress on one

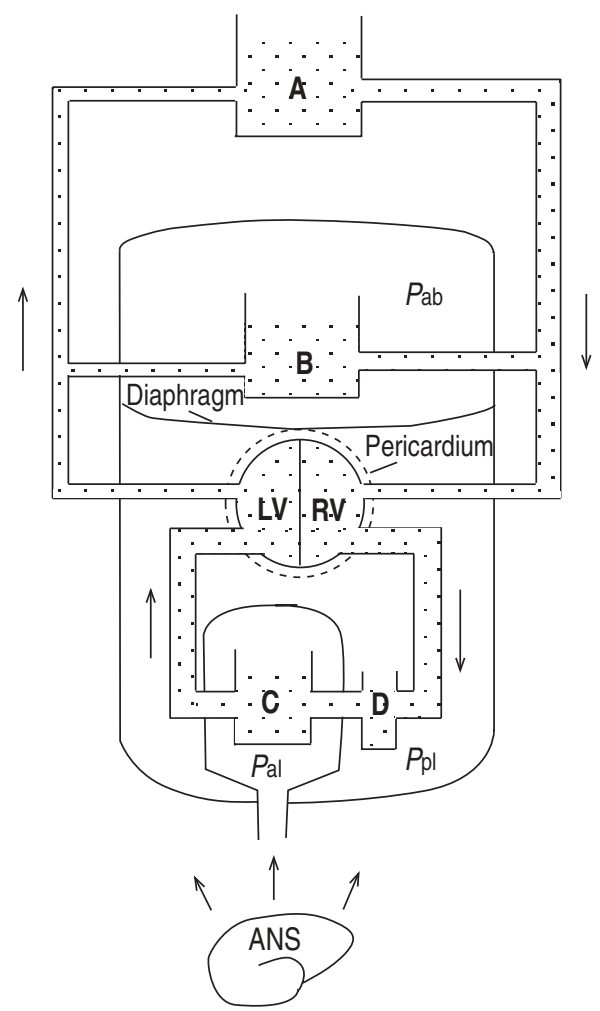

Fig. 2. - Slightly more complete model of the circulation. The following elements have been added to the model shown in figure 1 . The systemic circulation is divided into a nonabdominal component (A), and an abdominal component (B), the latter surrounded by abdominal pressure $(P$ ab $)$. Mean systemic pressure $\left(\bar{P}_{\text {syst }}\right)$ is now the weighted mean of the pressures in $\mathrm{A}$ and $\mathrm{B}$, and $\bar{R} \mathrm{v}$ the weighed mean of the venous resistance of $\mathrm{A}$ and $\mathrm{B}$. The heart is divided into right and left ventricles (RV and LV), and surrounded by the pericardium and pleural pressure $(P \mathrm{pl})$. The pulmonary circulation is depicted, composed of alveolar vessels $(\mathrm{C})$ surrounded by alveolar pressure $(P \mathrm{~A})$ and extra-alveolar vessels (D) surrounded by pleural pressure $(P \mathrm{pl})$. The autonomic nervous system (ANS) is indicated, with its influence over many of the elements shown. 
ventricle caused by expansion of the other ventricle; and stress on abdominal vessels. These have been described in detail in a recent review [16], and will only be summarized here.

Stress on the surface of the heart. An increase in pressure on the surface of the right heart will elevate $P$ ra. Since $P$ ra is the downstream pressure for venous return, this will decrease venous return. Because the entire pressure gradient for venous return is about $5 \mathrm{mmHg}$, increases of $P$ ra of only this magnitude would be fatal without compensatory mechanisms. These mechanisms include sympathetic reflexes [17], fluid and sodium retention that elevate $\bar{P}_{\text {syst }}$ and attenuate the fall in venous return.

Decreases in $P$ ra, in contrast, will increase venous return up to its maximum when $P$ ra becomes subatmospheric. A consequence of venous flow limitation is that more vigorous inspiratory efforts, though they further lower $P \mathrm{pl}$, will not further increase venous return once $P$ ra falls below atmospheric pressure. Another consequence is that $P$ ra can fall more before venous return becomes limited when it begins at a high level than when it begins near zero. That is, the potential for respiratory-induced fluctuations in venous return is greater at high $P$ ra.

At constant lung volume, changes in $P$ pl will change the pressure on the surface of the pulmonary vessels and left ventricle (LV) equally. They will, therefore, have no effect on the pressure gradient determining LV filling. However, they will alter determinants of LV emptying. Left ventricular afterload, which may be defined as the LV wall stress during ejection [18], is directly proportional to the systolic transmural LV pressure. Since the pressure on the external surface of the LV is usually near zero, it is often ignored in clinical situations. $\mathrm{LV}$ afterload is then considered to be proportional to arterial pressure, reflecting the pressure on the inner surface of the LV during ejection. However, during respiratory manoeuvres or disease states, $P$ pl can vary far from atmospheric. As pleural pressure falls, at constant arterial pressure, the LV must develop more tension to eject blood from the thorax. Conversely, increased $P \mathrm{pl}$ decreases the tension the muscle must develop to eject against a constant arterial pressure. Thus, changes in $P$ pl are equal to, but directionally opposite, changes in arterial pressure, in their effects on LV afterload [19-23].

Stress on intrapulmonary vessels. Changes in $P \mathrm{pl}$ at constant lung volume do not directly change the stress on pulmonary vessels, because alveolar and pleural pressures change equally. Stress on pulmonary vessels is increased by lung inflation. Due to the differing pressures on their surface, intra-alveolar and extra-alveolar vessels differ in their response to changes in lung volume. Extra-alveolar vessels enlarge with increases in lung volume. This decreases their resistance and increases their capacitance. Intra-alveolar vessels are compressed with increases in lung volume. The effects on their resistance and capacitance varies, depending upon their initial conditions, as follows [14].

Alveolar vessels are distended with blood when left atrial pressure $(P$ la $)$ exceeds $P$ A, corresponding to zone III. Lung inflation then decreases their capacitance, and may slightly increase their resistance. When $P$ A exceeds
$P$ la (zone II), alveolar vessels are relatively empty of blood. In zone II, flow limitation occurs in the pulmonary vessels. Pulmonary venous flow becomes independent of $P$ la, and the right ventricle (RV) can be said to eject against $P$ A, rather than $P_{1}$ [8]. Lung inflation beginning under zone II conditions will not change alveolar vessel capacitance (since they contain little blood), but will increase the pressure against which the RV ejects.

Taken together, these effects cause a biphasic response of pulmonary vascular resistance (PVR) to lung inflation. At low lung volumes (below functional residual capacity (FRC)), inflation decreases PVR. At higher lung volumes, inflation increases resistance [24]. The effect of lung inflation on pulmonary blood volume is similarly biphasic. At low blood volume, lung inflation will increase pulmonary blood volume due to increased extraalveolar capacitance. At high blood volume, effects on distended alveolar vessels predominate, and inflation will express blood from the lung [14, 25].

Stress on one ventricle from distension of the other. The two ventricles share a common septum and pericardium. Therefore, distension of one ventricle can alter both the diastolic and systolic function of the other through their interdependence. Distension of the RV impedes filling of the LV, both through shifts of the interventricular septum and generalized increases in pericardial pressure [26]. Increased pericardial pressure, like increased $P$ pl, can also decrease LV afterload [27]. The magnitude of this interdependence varies with the condition of the pericardium. It is increased when the pericardium is distended and, therefore, less compliant. When the pericardium is normally compliant, interdependence can also be exaggerated by increased lung volume because the cardiac fossa becomes less distensible [28, 29].

Stress on abdominal vessels. Increases in $P$ ab increase the pressure on the surface of abdominal vessels. Since the splanchnic vasculature contains $50 \%$ of the systemic capacitance and supports about $30 \%$ of total blood flow [30], changes in $P$ ab can have substantial mechanical effects on the circulation.

When the lungs are inflated with a positive pressure ventilator and the diaphragm does not contract, the rise in $P$ ab and $P$ pl will be approximately equally. Therefore, there is no change in the pressure gradient returning blood from the abdomen to the right atrium. Spontaneous inspiration, however, is not the simple inverse of positive pressure ventilation, because $P$ ab during spontaneous breathing changes in the direction opposite to $P$ pl. Studies in normals suggest that inspiration occurs along the relaxation pressure-volume relations of the chest and abdomen [31]. That is, the chest and abdominal distribution of a tidal volume is the same during spontaneous or positive pressure breaths. For the same tidal volume, $P$ ab would, therefore, increase equally. However, it is not known whether this also holds in disease states, and there is little reason to suspect that it would. Patients exhibiting abdominal alternans vary the distribution of tidal volumes from breath to breath. Even if the tidal changes in $P$ ab were identical during positive pressure and spontaneous breathing, changes in duty cycle (inspiratory time/period) would alter mean $P$ ab between the two modes. Therefore, when patients change from 
positive pressure to spontaneous breathing, $P$ ab may rise, fall, or remain constant.

Irrespective of how $P \mathrm{ab}$ changes relative to atmospheric pressure during spontaneous breathing compared to its value during positive pressure ventilation, $P$ ab always rises relative to $P \mathrm{pl}$ when the diaphragm contracts. This can produce substantial transient effects on blood flow through the inferior vena cava (IVC). The effects of $P$ ab on systemic venous flow bears similarity to the effects of $P$ A on pulmonary venous flow. Indeed, the conditions have been analysed as constituting "zones of the abdomen". When abdominal vessels are distended and intravascular pressure exceeds $P$ ab ("zone III"), contraction of the diaphragm increases IVC flow. However, when $P$ ab exceeds intravascular pressure, contraction of the diaphragm decreases IVC flow. This is analogous to the effect of lung inflation from zone II conditions $[32,33]$

Humoral and reflex effects. The previous discussion considered each of four stresses in isolation. In an intact circulation, it would be impossible to change a single stress without altering others. This is due not only to the mechanical complexity of the system, but also to reflex and humoral control mechanisms. The responses to respiratory-induced perturbations in the circulation include baroreflexes initiated by changes in arterial pressure, lung stretch reflexes, and humoral responses, such as atrial natriuretic factor. The interested reader is referred to a more detailed review [1]. The role of specific mechanisms in response to specific respiratory stresses is largely unknown.

\section{Clinical applications}

In the intact patient, the mechanisms discussed above integrate to produce effects which may be classified as either transient or steady-state. Transient effects refer to changes occurring through a respiratory cycle or to unsustained effects of a respiratory manoeuvre. Because of their rapidity, they are primarily mechanical in origin. They give rise to many of the clinical signs of disease. Of greater significance to the patient are steady-state effects. These produce sustained changes in cardiac output or its distribution through mechanical effects and their reflex and hormonal compensation.

\section{Transient effects}

Pulsus paradoxus. Pulsus paradoxus, as originally described by Kussmaul [34], referred to the disappearance of the radial pulse during inspiration, while the apical pulse remained palpable. Currently, the term describes a greater than $10 \mathrm{mmHg}$ inspiratory decrease in systolic arterial pressure. Pulsus paradoxus is associated with several conditions, including pericardial tamponade, severe asthma, and hypovolaemia. Somewhat different mechanical mechanisms contribute to the sign in each setting.

In pericardial tamponade, the distended pericardium is near its elastic limit. Pra is elevated, and $\bar{P}_{\text {syst }}$ is elevated to a lesser degree. Inspiration, by lowering $P$ ra, increases the pressure gradient for venous return. However, the distended pericardium can accommodate little increase in volume. Increased systemic venous return to the right atrium necessitates decreased pulmonary venous return to the left atrium. Therefore, LV stroke volume decreases during inspiration, primarily through a reduction in LV filling. During the subsequent expiration, blood retained in the pulmonary vessels refills the LV, and LV stroke volume increases. Thus, the expiratory increase in blood pressure largely reflects inspiratory increases in venous return, which are placed out of phase with respiration by their delay through the pulmonary circulation $[35,36]$.

In severe asthma, ventricular interdependence also contributes to pulsus paradoxus. Although the pericardium is normal, the cardiac fossa is stiffened by hyperinflation of the lungs [28]. Interdependence has been demonstrated by leftward displacement of the interventricular septum during inspiration [37]. In contrast to tamponade, however, the Pra is relatively low during expiration. This is due, in part, to sustained inspiratory muscle tone, which reduces expiratory $P \mathrm{pl}[38,39]$, and is exacerbated by hypovolaemia. Therefore, inspiratory effort, though supranormal, quickly lowers $P$ ra below atmospheric pressure and venous return becomes maximal. This limits the potential degree of ventricular interdependence, compared to the situation in pericardial tamponade.

In asthma but not tamponade, $P$ pl falls to markedly low levels during inspiration [39]. This extreme inspiratory reduction in $P$ pl increases LV afterload. If increased afterload is sustained, the normal heart will increase its contractility after a few beats in a phenomenon known as homeometric autoregulation [40]. Homeometric autoregulation is unlikely to occur within a single inspiration, however. LV stroke volume, therefore, falls due to the combined effects of ventricular interdependence, which decreases LV filling, and increased afterload, which impedes LV emptying.

The cause of pulsus paradoxus during hypovolaemia is less well studied, but can be inferred from the basic stresses involved. Pericardial compliance, lung volume, and tidal changes in $P \mathrm{pl}$ are all near normal, and $P$ ra is low. Effects of interdependence and LV afterload could, therefore, be predicted to be minimal. However, hypovolaemia would place large portions of the lungs in zone II. Inspiration would then increase the capacitance of the extra-alveolar vessels, and increase RV afterload through its effect on alveolar vessels [25]. Inspiration in zone II conditions, therefore, decreases LV filling by decreasing pulmonary venous flow. This is most likely the primary cause of pulsus paradoxus in hypovolaemia.

Kussmaul's sign. Kussmaul's sign, an inspiratory increase in $P$ ra, was originally described in constrictive tuberculous pericarditis [34], and is occasionally seen in RV failure from infarction or pulmonary embolism [41]. It is clear how the inspiratory decrease in pleural pressure would lower $P$ ra relative to $\bar{P}_{\text {syst }}$ and promote venous return. However, no matter how rigid the pericardium, the decrease in $P$ ra relative to $\bar{P}_{\text {syst }}$ alone could never elevate $P$ ra relative to atmospheric pressure. Consider an instantaneous decrease in $P$ pl. Before there was any change in flow into or out of the right heart, $P$ ra would 
fall by an amount equal to the fall in $P$ pl. As venous return increased, $P$ ra would begin to return to its expiratory level, at a rate determined by the relative rates of RV emptying and filling. However, as $P$ ra approached its expiratory level, the pressure difference between $\bar{P}_{\text {syst }}$ and $P$ ra would also approach its expiratory value, and venous flow would return to its expiratory rate. Thus, a uniform decrease in $P$ pl could, at most, cause $P$ ra to fall transiently and return to, but not above, its expiratory level. Pericardial rigidity would reduce the volume changes of the atrium, but would not increase its internal pressure.

For Kussmaul's sign to occur, one of two additional conditions must be met. Either pressure surrounding the heart must rise in excess of pressure elsewhere in the thorax, or $\bar{P}_{\text {syst }}$ must rise during inspiration. Since the pericardium is tethered to the diaphragm via ligaments, diaphragmatic contraction can compress the heart even as it lowers $P \mathrm{pl}$ elsewhere. This was demonstrated in cadavers by Dock [42], who attributed the notion to Richard Lower in 1669. If this were the case, Kussmaul's sign should be accompanied by decreased flow into the right atrium. Alternatively, $\bar{P}_{\text {syst }}$ could rise because of the inspiratory increase in $P$ ab. This possibility was examined by TAKATA et al. [43]. In an intact anaesthetized canine preparation, they found that Kussmaul's sign would occur with phrenic nerve stimulation during hypervolaemic conditions only when the airway was open. This allowed inspiration and diaphragmatic descent, and was accompanied by increased IVC flow. In contrast, the same fall in $P \mathrm{pl}$ with the airway occluded failed to increase IVC flow or produce Kussmaul's sign [43]. This suggests that the increase in $P \mathrm{ab}$ is essential. In constrictive pericarditis, $\bar{P}_{\text {syst }}$ is elevated and the abdomen is in zone III. Inspiratory increases in $P$ ab will then increase IVC flow. Inflow into the noncompliant pericardium is sufficiently great to raise $P$ ra even as $P$ pl is falling.

Valsalva and Müller manoeuvres. The Valsalva manoeuvre is a sustained volitional contraction of expiratory muscles against a closed glottis, which raises $P$ pl and $P$ ab at constant lung volume. The normal response of arterial pressure to the Valsalva manoeuvre is divided into four phases. At the beginning of strain, arterial pressure increases. Next, systolic and pulse pressure falls, with reflex cardioacceleration. As strain is released, there is a momentary further decrease in pressure. Finally, during recovery, arterial pressure overshoots and gradually returns to its baseline. In patients with congestive heart failure, however, an abnormal second phase called the "square-wave response" has been described. Arterial pressure rises normally, but then remains elevated for as long as straining is sustained [44]. Computer-based analysis of the plethysmographic pulse-pressure in a finger during a Valsalva manoeuvre has been shown to distinguish between patients with normal and elevated pulmonary capillary occlusion pressure, based on the presence of a square-wave response [45]. The same data can be obtained manually in any co-operative patient with an indwelling arterial catheter. The Valsalva manoeuvre can be used repetitively to assess global cardiac function and preload.

The square-wave response reflects the effects on the failing ventricle of changes in preload and afterload. A normal cardiac function curve (the relationship between preload and cardiac output) is steep, depicting a large change in output for a small change in preload. The function curve of a failing heart is flat, i.e. output is insensitive to preload. Conversely, the failing heart is more sensitive to changes in afterload than is the normal heart. That is, the cardiac function curve will shift further upward in response to reduced afterload [46]. Changes in preload and afterload affect stroke volume in opposite directions, i.e. a decrease in preload would tend to decrease stroke volume while an decrease in afterload will tend to increase stroke volume.

How are preload and afterload altered during the Valsalva manoeuvre? Returning to figure 2, the stress on the surface of the heart, pulmonary, and abdominal vessels will be increased relative to the remainder of the circulation. For the RV, this will elevate $P$ ra relative to $\bar{P}$ syst, decreasing the gradient for venous return. As implied by the flat cardiac function curve of a failing RV, however, any decreases in end-diastolic volume will cause similar changes in end-systolic volume. As the RV gets smaller, stroke volume will be preserved.

Through ventricular interdependence, filling of the LV may be improved by decreased venous return to the RV. Because stress on the surface of the RV, pulmonary vessels, and LV increases equally, there would be no other effects on flow between these three points. However, the increase in pressure surrounding the LV relative to the nonabdominal vasculature would decrease LV afterload. The failing LV is more responsive to changes in afterload than the normal heart. Thus, the end-diastolic volume of the LV could increase (through ventricular interdependence) and the end-systolic volume decrease (through afterload reduction). Stroke volume would increase.

At first glance, these effects would appear to be transient. After a period of time, RV preload would fall sufficiently so that RV stroke volume would decrease, the distended pulmonary capacitance vessels would begin to discharge themselves into the LV, and lastly LV stroke volume would decay. Indeed, this would probably occur in many patients with congestive heart failure if the Valsalva manoeuvre were continued beyond 10-15 s. However, it may be shown mathematically that, given sufficiently poor cardiac function and hypervolaemia, increases in $P \mathrm{pl}$ can result in sustained increases in cardiac output [47].

The Müller manoeuvre is a prolonged inspiratory effort made at constant lung volume. It is not a complete mirror image of the Valsalva manoeuvre, however. Because $P$ ab rises with diaphragmatic contraction while the $P \mathrm{pl}$ falls, the increase in RV preload and LV afterload is greater than their converse during the Valsalva manoeuvre, for the same but directionally opposite changes in $P$ pl. When normal subjects and patients with coronary artery disease were compared, the Müller manoeuvre decreased radionuclide ejection fraction only in patients with coronary artery disease (fig. 3). Regional abnormalities in LV wall motion were elicited only in patients with prior transmural infarction [49]. Although this finding has not been tested in large populations, the Müller manoeuvre may be useful to elicit subclinical cardiac dysfunction. 


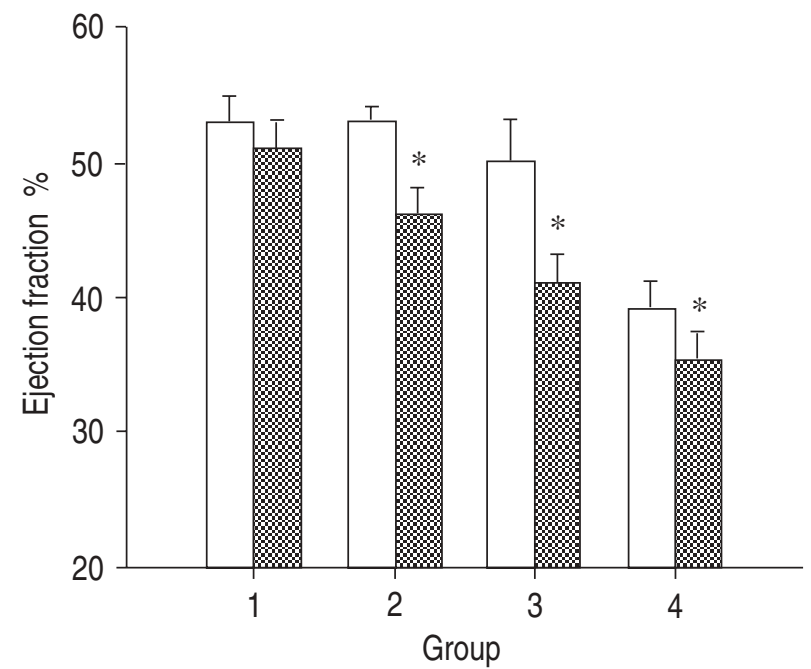

Fig. 3. - Effects of a Müller manoeuvre on ejection fraction. Subjects sustained an obstructed inspiratory effort to -20 to $-40 \mathrm{cmH}_{2} \mathrm{O}$ at residual volume for 20-25 s, while ejection fraction was measured by radionuclide ventriculography. Groups consisted of: 1) normal controls $(\mathrm{n}=13)$; 2) patients with coronary artery disease without myocardial infarction $(\mathrm{n}=25)$; 3) patients with a history of nontransmural infarction $(n=13)$; and 4) patients with history of transmural infarction ( $\mathrm{n}=36)$. $\otimes$ : relaxed; $\square$ : Müller manoevre. ${ }^{*}: \mathrm{p}<0.01$, significantly different from relaxed. (Drawn from data in [48]).

\section{Steady-state effects}

Positive end-expiratory pressure and continuous positive airway pressure $(C P A P)$. PEEP generally decreases cardiac output, and the cause of this decrease has been the focus of much research over the past decade. A few studies in intact animals or humans have suggested impairment of cardiac contractility on PEEP [48, 50]. Manny et al. [51] perfused an isolated heart with blood from a support dog. When the support dog was placed on PEEP, cardiac function curves of the isolated heart were depressed. This myocardial dysfunction was not observed when $P$ pl was increased at constant lung volume in the support dogs. Other studies also found evidence of stress on the surface of the ventricles by the expanded lung [30], altering ventricular shape or diastolic compliance $[23,52,53]$. Most studies, however, have failed to demonstrate PEEP-induced depression of cardiac function curves $[23,54,55]$ or end-systolic pressure-volume relationships $[56,57]$, provided the elevated pressures within the cardiac chambers are correctly referenced to the pressures on their surface. Thus, in intact animals or humans, it appears likely that any humorally-mediated cardiac depression is subtle or is overcome by simultaneous sympathetic stimulation [17].

Many investigators have, therefore, concluded that the most important cause of decreased cardiac output on PEEP is the increase in $P$ ra, which decreases venous return $[23,54,55,57,58]$. This reasoning implies that $P$ ra rises relative to the upstream pressure driving venous return, $\bar{P}$ syst. However, several studies in animals and humans have recently demonstrated that PEEP increases $\bar{P}_{\text {syst }}$ and $P$ ra equally [59-61]. That is, the pressure driving venous return is unaltered. The increase in $\bar{P}_{\text {syst }}$ occurs primarily through activation of neurovascular reflexes, which decrease vascular capacitance [62], and through transfer of blood from the pulmonary to systemic circulations [63].
If there is no change in the pressure driving venous return yet flow falls, PEEP must increase venous resistance. In canine studies, PEEP has been shown both to increase the venous resistance and increase the $P$ ra below which venous return becomes maximal (fig. 4) [59, $60]$. This is due to focal compression of the great veins, which was demonstrable in the IVC in dogs by use of magnetic resonance imaging (MRI) (fig. 5) [64]. In images of the author breathholding at total lung capacity (TLC), similar compression was not observed (fig. 6). However, IVC compression by the hyperinflated lungs has been shown angiographically in some patients with severe emphysema [65]. Even if PEEP does not directly compress the great veins, it could increase venous resistance by altering the distribution of arterial flow to regions that drain more slowly [11].

Several of these effects of PEEP are modified in the ill. By increasing the pressure on the surface of the LV, PEEP also decreases LV afterload. As with the Valsalva manoeuvre, this may explain the occasional report of patients with congestive heart failure in whom cardiac output rises with PEEP [66]. Decreased arterial pressure and increased pressure on the surface of the ventricles can compromise the pressure gradient driving coronary flow [67], and may induce coronary ischaemia in some patients despite the decrease in cardiac work [68, 69].

Increased cardiac output or LV ejection fraction has also been reported when spontaneously breathing patients with congestive heart failure are placed on low levels of CPAP [70, 71]. Given the rather trivial increases in $P$ pl to be expected from $5 \mathrm{cmH}_{2} \mathrm{O}$ CPAP, it is difficult to fully explain this finding based on changes in LV afterload due to changes in surface pressure alone. Another possible contributing mechanism is decreased respiratory effort on CPAP, such that the increase in mean $P$ pl exceeds what would be predicted by the increase in end-expiratory $P$ pl. In addition, studies in lightly sedated

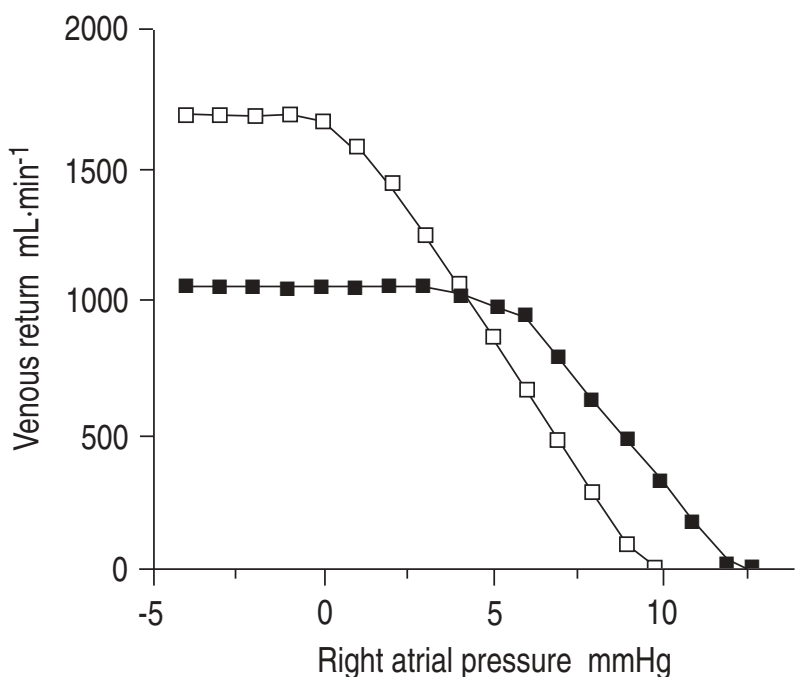

Fig. 4. - Canine venous return curve with (ロ) and without (๖) 10 $\mathrm{mmHg}\left(14 \mathrm{cmH}_{2} \mathrm{O}\right)$ positive end-expiratory pressure (PEEP). Data were obtained from eight animals with a right heart bypass preparation similar to that used by GUYTON [6]. PEEP increased the 0 flow, $\mathrm{x}$-axis intercept, which approximates mean systemic pressure $\left(\bar{P}_{\text {syst }}\right)$, decreased the slope of the relationship (increased venous resistance), and increased the right atrial pressure $\left(P_{\text {ra }}\right)$ below which flow became maximal. (Reprinted from [59], with permission). 
a)

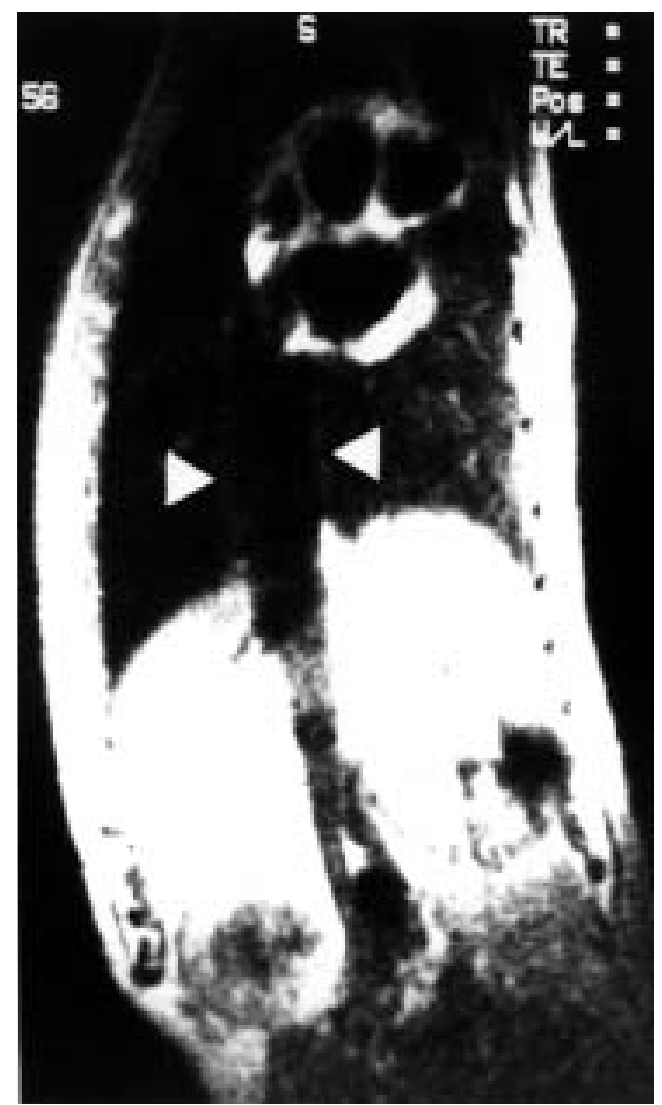

b)

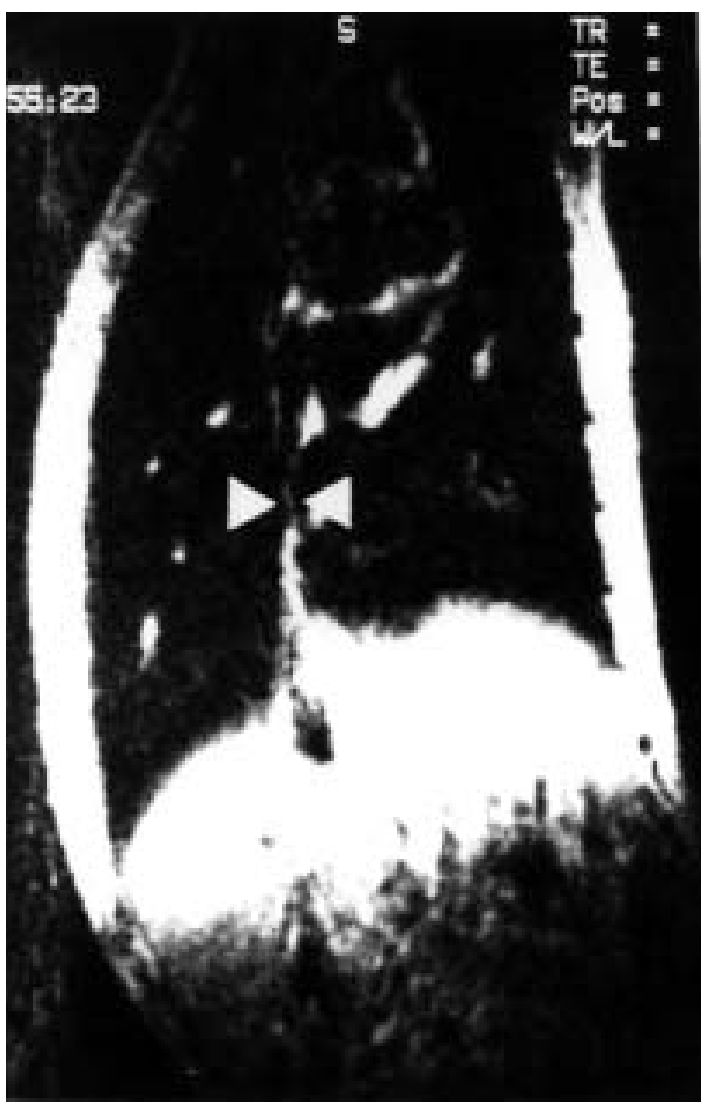

Fig. 5. - Magnetic resonance images from an anaesthetized dog: a) without positive end-expiratory pressure (PEEP); and b) with $10 \mathrm{mmHg}$ PEEP. Images were obtained with the animal in the left lateral decubitus position, but are rotated upright for viewing. Images are shown in a near-coronal plane aligned with the long axis of the inferior vena cava (IVC). The lateral walls of the IVC are indicated by arrowheads, and focal compression is seen on PEEP. (Reprinted from [64], with permission).

a)

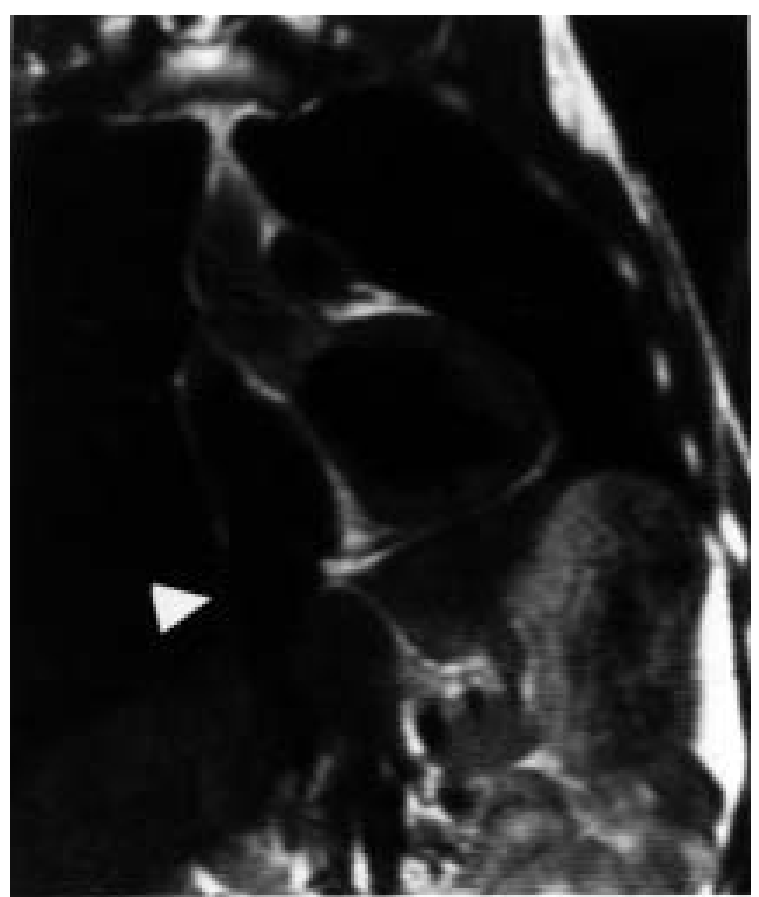

b)

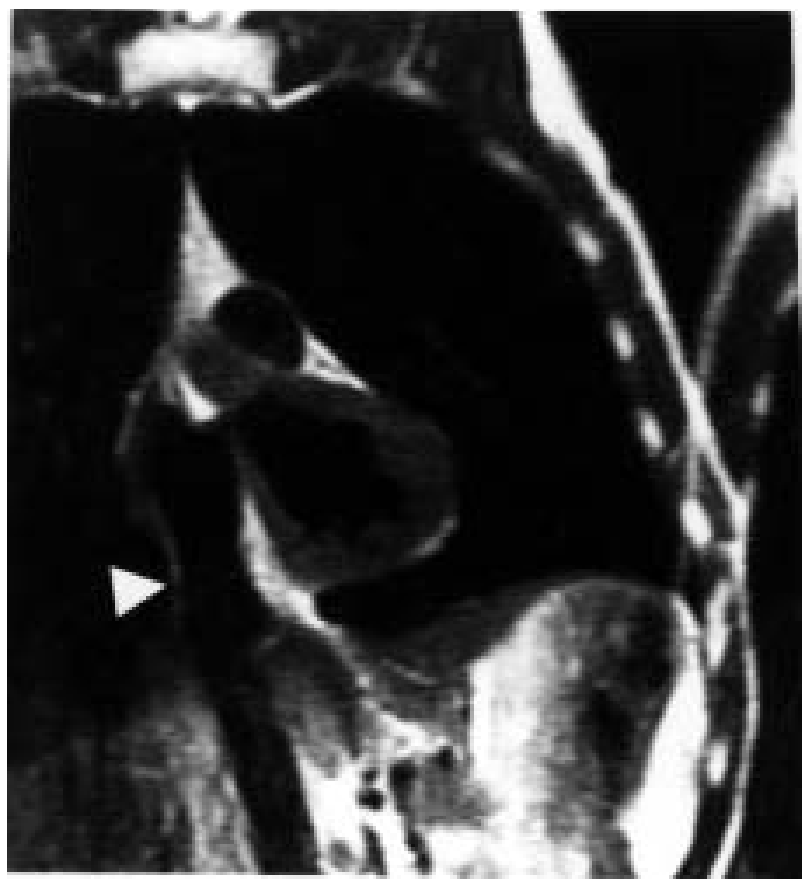

Fig. 6. - Similar images of the author in the left lateral decubitus position: a) at functional residual capacity, relaxed end-expiration; and b) breathholding, at total lung capacity. Although the interior vena cava (IVC) narrows during breathholding, complete compression is not observed in these nor in sagitally reconstructed planes. 
pigs with pacing-induced heart failure suggest that CPAP caused reflex improvement in myocardial contractility or vasodilatation [72]. Thus, cardiac function may improve through several mechanisms.

In patients with acute cardiogenic pulmonary oedema progressing to respiratory failure, CPAP has been shown to obviate the need for emergency intubation [73, 74]. In this setting, it is a virtually instantaneous and readily reversible means to decrease preload and afterload. In addition, it can improve oxygenation and decrease respiratory effort. This makes it an attractive temporizing measure, while awaiting other interventions to take effect.

PEEP is frequently used in the management of acute respiratory distress syndrome. Since lung compliance is reduced, one would anticipate that PEEP would cause a lesser increase in lung volume and $P$ pl than it would were the lungs normal. An animal study of acute lung injury found that the haemodynamic effects of PEEP were similar with normal or injured lungs, despite lower $P$ pls during expiration in the former case [75]. These authors hypothesized that beneficial effects of reduced transmission of airway pressure to the heart during expirations are counteracted by the higher inspiratory airway pressures in injured lungs [75]. Intravascular volume status may alter the haemodynamic effects of PEEP. Likewise, drugs with adrenergic blocking activity will attenuate the reflex compensatory responses to PEEP [17].

Weaning. The major mechanical effect of switching from positive-pressure to spontaneous breathing is a decrease in mean $P$ pl. In addition, there are likely to be alterations in mean lung volume as tidal volume and duty cycle change. The cardiovascular consequences of lower pressure on the surface of the heart is an increase in the pressure gradient driving venous return, and an increase in the afterload of the LV. Again, with normal biventricular function, preload effects predominate and cardiac output is usually higher during spontaneous breathing.

Lung and respiratory muscle function are generally considered the limiting factors governing weaning. However, patients are occasionally encountered whose lung mechanics and respiratory muscle function would appear to predict successful weaning, but who rapidly fail during trials of spontaneous breathing. In these patients, circulatory effects of heart-lung interactions may impair weaning. LEMAIRE et al. [76] studied 15 such patients with combined cardiac failure and respiratory disease. Despite encouraging weaning parameters and normal right atrial and pulmonary artery occlusion pressures, none of the patients would tolerate trials of T-piece breathing. Notably, the $P$ ra in these patients was higher during spontaneous breathing than during positive pressure breathing, which one would not have anticipated from the changes in their $P$ pl. After 1 week of diuresis, patients lost an average of $5 \mathrm{~kg}$, with no change in baseline $P$ ra or respiratory weaning parameters. Eight of these patients weaned successfully, now associated with a fall in $P$ ra from positive pressure to spontaneous breathing.

Although the transition from positive pressure to spontaneous breathing would be expected to increase LV afterload (decrease $P$ pl), this effect would be the same before and after diuresis. Virtually the only factor that could cause $P$ ra to rise when changing from positive pressure to spontaneous breathing is an increase in $\bar{P}_{\text {syst, }}$ as has been considered regarding Kussmaul's sign. Why, then, would $\bar{P}_{\text {syst }}$ rise prior to, but not after diuresis? The answer becomes clear if one accepts that $P$ ab may be higher during spontaneous than during positive pressure breathing. Prior to diuresis, the abdomen was in zone III. The increase in pressure on the surface of distended abdominal vessels increased IVC flow, and this caused cardiac decompensation. After diuresis, the abdomen was in zone II. The same increase in $P$ ab when changing to spontaneous breathing no longer increased IVC flow, and patients could wean without initiating a relentless spiral to cardiac failure. In such patients with limited cardiac reserve, considerations of heart-lung interactions provide the insight into otherwise inexplicable weaning failure.

Adequate systemic blood flow is also necessary to ensure perfusion of respiratory muscles during weaning. In the critically ill, respiratory muscles may require up to $20 \%$ of total body oxygen consumption [77-79]. Respiratory muscles fail during cardiogenic shock [80], and contribute to systemic lactic acidosis during lowoutput states [81]. Conversely, fatiguing diaphragm increases its force of contraction with increases in blood flow $[82,83]$. Hyperinflation, coupled with the expiratory muscle recruitment that occurs with dyspnoea, may decrease blood flow to respiratory muscles even when systemic haemodynamics appear adequate [84]. Thus, another cause of enigmatic weaning failure may be relative respiratory muscle ischaemia.

Cardiopulmonary resuscitation. When the heart is arrested, heart-lung interactions become lifesaving. Virtually since the first consideration of closed chest resuscitation, the mechanism whereby compression of the chest generates blood flow has been a source of controversy $[85,86]$. The "thoracic pump" theory maintains that the generalized increase in $P \mathrm{pl}$ during chest compression causes blood to be discharged from all intrathoracic vascular structures. The heart serves as a passive conduit. Retrograde flow is prevented by venous valves, compression of veins near the thoracic inlet, or by the relative time constants of the arterial and venous systems. The "cardiac pump" theory maintains that external chest pressure squeezes the heart directly, compressing it between the sternum and vertebral column.

The thoracic pump theory is supported by several lines of evidence. CRILEY et al. [85] reported that consciousness could be maintained by coughing during cardiac arrest, with no chest compression. Cardiopulmonary resuscitation (CPR) pressures and flows are higher when they occur simultaneous with lung inflation, which would tend to prevent direct cardiac compression [87, 88]. Effective CPR can be provided by a circumferential inflatable vest, which does not compress the heart [89, 90]. Several studies have demonstrated equal increases in pleural and all intrathoracic vascular pressures during compression $[87,88]$. Imaging studies have shown the mitral valve remains open during chest compression, a finding incompatible with the cardiac pump theory [91, 92]. Cardiac output has been shown to be independent of rate but dependent upon duty cycle (compression 
time/period). This suggests that stroke volume is dependent upon the time constants of arterial and venous drainage, as the thoracic pump theory would predict [93].

However, equally persuasive experimental evidence supports the cardiac pump theory. In some studies, compression rate was an important determinant of cardiac output [94]. Studies of "high impact" CPR have shown greater increases in intravascular than pleural pressure [94]. Some echocardiographic studies have shown mitral valve closure and decreased left ventricular volume during compression $[95,96]$. There are major differences between these studies regarding the species used (humans, dogs or pigs), whose thoracic anatomy may influence the findings. There were also differences in the technique of CPR and resuscitation protocols between studies, which may partially explain the contradictory conclusions.

One such factor is the stress upon the surface of the pulmonary blood vessels, which will vary with different techniques of CPR. Aggressive volume resuscitation will distend the alveolar vessels. Lung inflation will then increase pulmonary venous flow. When combined with chest compression, lung inflation would tend to keep the mitral valve open and keep left ventricular volume constant. In contrast, if chest compression were allowed to decrease lung volume, pulmonary vascular capacitance could increase and the mitral valve transiently close, even without direct cardiac compression. This was demonstrated by BEATTIE et al. [97] in dogs. Thus, it is likely that both thoracic and cardiac pump mechanisms contribute to forward blood flow to a variable degree. Neither mechanism may be distinguishable by the state of mitral valve closure.

Although the factors determining cardiac output are quite different in the arrested and beating heart, the determinants of venous return are identical and are independent of cardiac function. Venous return is still governed by the difference between $\bar{P}_{\text {syst }}$ and $P$ ra and the resistance to venous return. These factors, particularly the extent to which $P$ ra is lowered during the release phase, may be modified by CPR technique.

Simultaneous compression and ventilation CPR (SCVCPR) was studied in large clinical trials because stroke volume was shown to be greater in some animal experiments using this technique $[87,98]$. However, the outcome in clinical trials was disappointing [99]. One reason for this is that breath-stacking occurs when ventilation is as rapid as typical compression rates. This elevates $P \mathrm{pl}$ and $P$ ra during the release phase [100], and impedes venous return. Such breath-stacking is inevitable despite the forced expiration caused by chest compression, because expiration is flow-limited. This is especially true in patients with obstructive lung disease. Thus, SCVCPR, despite promising animal studies, was never likely to be useful in patients with smoking as a shared risk factor for coronary and pulmonary disease.

Other techniques can manipulate the determinants of venous return to improve CPR blood flow. Active compression-decompression CPR (ACD-CPR) uses a suction cup device to actively re-expand the thorax. This results in more negative $P$ pls than standard techniques, which can increase venous return. Still greater coronary and cerebral flows are achieved when inspiration is prevented during chest decompression, resulting in more negative $P$ pls $[101,102]$. However, since venous return is maximal when $P$ ra falls below zero, the potential benefit of this technique is limited and would be still less in patients who arrest from or with hypovolaemia.

Abdominal compression during the release phase has been shown to increase cardiac output, coronary perfusion pressure, and cardioversion rate in some studies $[103,104]$. Compression of the aorta with redirection of flow to the brain and heart may explain these results [105]. In addition, the increase in pressure on the surface of distended abdominal vessels would increase the effective $\bar{P}_{\text {syst }}$ and, thereby, increase venous return. Many variations of these modified CPR techniques are undergoing animal and human testing.

\section{Summary}

Since the respiratory and circulatory systems are anatomically linked and both driven by pressure, their mechanical interaction is inevitable. Under normal circumstances, these effects are of interest to physiologists and clinicians, but are subtle. In the critically ill, exaggerated respiratory stresses and limited circulatory reserve magnify these normal responses. Medical interventions, such as positive pressure ventilation, positive end-expiratory pressure, and cardiopulmonary resuscitation introduce additional situations where the two systems can interact. Systematic consideration of a few basic stresses, modified by reflex responses, can allow the astute physician to understand, anticipate, or prevent effects that would otherwise appear baffling.

Acknowledgements: The author wishes to thank B. Jordan for her secretarial assistance, and R. Brower, S. Permutt, R. Wise, and J. Robotham for countless hours of discussion on the topics of this review.

\section{References}

1. Scharf S, Cassidy S. Heart-Lung Interactions in Health and Disease. Part 4. Indirect Heart-Lung Interactions. New York, Marcel Dekker Inc., 1989; pp. 339-418.

2. Sylvester JT, Goldberg HS, Permutt S. The role of the vasculature in the regulation of cardiac output. Clin Chest Med 1983; 4: 111-126.

3. Starling EH. On some points in the pathology of heart disease. Orris and Gale lecture. II. Lancet 1897; 1 : 652-655.

4. Starling EH. The effects of heart failure on the circulation. Lancet 1897; i: 652-655.

5. Guyton AC, Polizo D, Armstrong GG. Mean circulatory filling pressure measured immediately after cessation of heart pumping. Am J Physiol 1954; 179: 261-267.

6. Guyton AC. Determination of cardiac output by equating venous return curves with cardiac response curves. Physiol Rev 1955; 35: 123-129.

7. Pride NB, Permutt S, Riley RL, Bromberger-Barnea B. Determinants of maximal expiratory flow from the lungs. J Appl Physiol 1967; 23(5): 646-662.

8. Permutt S, Riley RL. Hemodynamics of collapsible vessels with tone: the vascular waterfall. J Appl Physiol 1963; 18: 924-932.

9. Greene AS, Shoukas AA. Changes in canine cardiac function and venous return curves by the carotid baroreflex. Am J Physiol 1986; 251: H288-H296. 
10. Brunner MJ, Shoukas AA, MacAnespie CL. The effect of the carotid sinus baroreceptor reflex on blood flow and volume redistribution in the total systemic vascular bed of the dog. Circ Res 1981; 48: 274-285.

11. Caldini P, Permutt S, Waddell JA, Riley RL. Effect of epinephrine on pressure, flow and volume relationships in the systemic circulation of dogs. Circ Res 1974; 34 : 606-623.

12. Shoukas AA, Sagawa K. Carotid sinus baroreceptor reflex control of total systemic vascular capacity. Circ Res 1974; 33: 22-33.

13. Greenway CV, Seaman KL, Innes IR. Norepinephrine on venous compliance and unstressed volume in cat liver. Am J Physiol 1985; 248: H468-H476.

14. Howell JBL, Permutt S, Proctor DF, Riley RL. Effect of inflation of the lung on different parts of pulmonary vascular bed. J Appl Physiol 1961; 16(I): 71-76.

15. Permutt $S$, Caldini P. Regulation of cardiac output by the circuit: venous return. In: Baan J, Noordergraaf A, Raines J, eds. Cardiovascular System Dynamics. Cambridge, The MIT Press, 1978; pp. 465-479.

16. Fessler HE, Permutt $S$. Interactions between the circulatory and ventilatory pumps. The Thorax. 2 nd edn. In: Roussos C, Macklem PT, eds. Lung Biology in Health and Disease. Vol. 85, New York, Marcel Dekker Inc., 1995.

17. Scharf SM, Ingram RH Jr. Influence of abdominal pressure and sympathetic vasoconstriction on the cardiovascular response to positive end-expiratory pressure. Am Rev Respir Dis 1977; 116: 661-670.

18. Regen DM. Calculation of left ventricular wall stress. Circ Res 1990; 67: 245-252.

19. Fessler HE, Brower RG, Wise RA, Permutt S. Mechanism of reduced LV afterload by systolic and diastolic positive pleural pressure. J Appl Physiol 1988; 65(3): 1244-1250.

20. Buda AJ, Pinsky MR, Ingels J, Daughters GT, Stinson $\mathrm{EB}$, Alderman EL. Effect of intrathoracic pressure on left ventricular performance. N Engl J Med 1992; 301: 453-459.

21. Peters J, Fraser C, Stuart RS, Baumgartner W, Robotham JL. Negative intrathoracic pressure decreases independently left ventricular filling and emptying. Am J Physiol 1989; 257: H120-H131.

22. Peters J, Kindred MK, Robotham JL. Transient analysis of cardiopulmonary interactions II. Systolic events. J Appl Physiol 1988; 64(4): 1518-1526.

23. Wise RA, Robotham JL, Bromberger-Barnea B, Permutt $S$. Effect of PEEP on left ventricular function in rightheart-bypassed dogs. J Appl Physiol: Respirat Environ Exercise Physiol 1981; 51(3): 541-546.

24. Burton AC, Patel DJ. Effect on pulmonary vascular resistance of inflation of the rabbit lungs. $J$ Appl Physiol 1958; 12(2): 239-246.

25. Brower R, Wise RA, Hassapoyannes C, BrombergerBarnea B, Permutt S. Effect of lung inflation on lung blood volume and pulmonary venous flow. $J$ Appl Physiol 1985; 58(3): 954-963.

26. Beyar R, Hausknecht MJ, Halperin HR, Yin FCP, Weisfeldt ML. Interaction between cardiac chambers and thoracic pressure in intact circulation. Am J Physiol 1987; 22: H1240-H1252.

27. Janicki JS, Weber KT. The pericardium and ventricular interaction, distensibility, and function. Am J Physiol 1980; 238: H494-H503.

28. Lloyd TC Jr. Mechanical cardiopulmonary interdependence. J Appl Physiol: Respirat Environ Exercise Physiol 1982; 52(2): 333-339.
29. Takata M, Robotham JL. Ventricular external constraint by the lung and pericardium during positive end-expiratory pressure. Am Rev Respir Dis 1991; 143: 872-875.

30. Mitzner W, Goldberg H. Effects of epinephrine on resistive and compliant properties of the canine vasculature. J Appl Physiol 1975; 39(2): 272-280.

31. Konno K, Mead J. Measurement of separate volume changes of rib cage and abdomen during breathing. $J$ Appl Physiol 1967; 22(4): 407-422.

32. Takata M, Wise RA, Robotham JL. Effects of abdominal pressure on venous return: abdominal vascular zone conditions. J Appl Physiol 1990; 69(6): 1961-1972.

33. Takata M, Robotham JL. Effects of inspiratory diaphragmatic descent on inferior vena caval venous return. J Appl Physiol 1992; 72(2): 597-607.

34. Kussmaul A. Ueber schwielige Mediastino-Pericarditis und den paradoxen Puls. Klin Wschr 1873; 37: 433-465.

35. Guntheroth WG, Morgan BC, Mullins GL. Effect of respiration on venous return and stroke volume in cardiac tamponade. Circ Res 1967; 20: 381-390.

36. Gabe IT, Mason DT, Gault JH, et al. Effect of respiration on venous return and stroke volume in cardiac tamponade. Br Heart J 1970; 32: 592-596.

37. Jardin F, Farcot J, Boisante L, Prost J, Gueret P, Bourdarias J. Mechanism of paradoxic pulse in bronchial asthma. Circulation 1982; 66(4): 887-894.

38. Martin J, Powell E, Shore S, Emrich J, Engel LA. The role of respiratory muscles in the hyperinflation of bronchial asthma. Am Rev Respir Dis 1980; 121: 441447.

39. Permutt S. Physiologic changes in the acute asthmatic attack. In: Austen KF, Lichtenstein LM, eds. Asthma: Physiology, Immunopharmacology and Treatment. New York, Academic Press Inc., 1973; pp. 15-27.

40. Sarnoff SJ, Mitchell JH, Gilmore JP, Remensnyder JP. Homeometric autoregulation in the heart. Circ Res 1960; 8: 1077-1091.

41. Cohen ST, Kupersmith J, Aroesty J, Rowe JW. Pulsus paradoxus and Kussmaul's sign in acute pulmonary embolism. Am J Cardiol 1973; 32(3): 271-275.

42. Dock W. Inspiratory traction on the pericardium. Arch Intern Med 1961; 108: 81-84.

43. Takata M, Beloucif S, Shimada M, Robotham JL. Superior and inferior vena cava flows during respiration: pathogenesis of Kussmaul's sign. Am J Physiol 1992; 262: H763-H770.

44. Zema MJ, Caccavano M, Kligfield P. Detection of left ventricular dysfunction in ambulatory subjects with the bedside Valsalva maneuver. Am J Med 1983; 75: 241248.

45. McIntyre KM, Vita JA, Lambrew CT, Freeman J, Loscalzo J. A noninvasive method of predicting pulmonarycapillary wedge pressure. N Engl J Med 1992; 327(24): 1715-1720.

46. Pouleur H, Covell JW, Ross J. Effects of nitroprusside on venous return and central blood volume in the absence and presence of acute heart failure. Circulation 1980; 61: 328-337.

47. Permutt $\mathrm{S}$, Wise RA, Sylvester JT. Interaction between the circulatory and ventilatory pumps. In: Roussos C, Macklem P, eds. The Thorax. Part B. New York, Marcel Dekker Inc., 1985; pp. 701-737.

48. Cassidy SS, Eschenbacher WL, Robertson CH Jr, Nixon JV, Blonqvist G, Johnson J, R.L. Cardiovascular effects of positive-pressure ventilation in normal subjects. $J$ Appl Physiol: Respirat Environ Exercise Physiol 1979; 47(2): 453-461. 
49. Scharf SM, Woods BO, Brown R, Parisi A, Miller MM, Tow DE. Effects of the Mueller maneuver on global and regional left ventricular function in angina pectoris with or without previous myocardial infarction. Am J Cardiol 1987; 59: 1305-1309.

50. Cassidy SS, Robertson CH Jr, Pierce AK, Johnson RL Jr. Cardiovascular effects of positive end-expiratory pressure in dogs. J Appl Physiol: Respirat Environ Exercise Physiol 1978; 44(5): 743-750.

51. Manny J, Grindlinger G, Mathe AA, Hechtman HB. Positive end-expiratory pressure, lung stretch, and decreased myocardial contractility. Surgery 1978; 84: 127-133.

52. Jardin F, Farcot J, Boisante L, Curien N, Margairaz A, Bourdarias J. Influence of positive end-expiratory pressure on left ventricular performance. $N$ Engl J Med 1981; 304: 387-392.

53. Cassidy SS, Mitchell JH, Johnson RL Jr. Dimensional analysis of right and left ventricles during positive-pressure ventilation in dogs. Am J Physiol 1982; 242: H549-H556.

54. Fewell JE, Abendschein DR, Carlson CJ, Rapaport E, Murray JF. Continuous positive-pressure ventilation does not alter ventricular pressure-volume relationship. Am J Physiol 1981; 240: H821-H826.

55. Marini JJ, Culver BH, Butler J. Effect of positive endexpiratory pressure on canine ventricular function curves. J Appl Physiol: Respirat Environ Exercise Physiol 1981; 51: 1367-1374.

56. Crottogini AJ, Willshaw P, Barra JG, Breitbart GJ, Pichel RH. End-systolic pressure-volume relationships in dogs during ventilation with PEEP. Am J Physiol 1988; 23: H664-H670.

57. Johnston WE, Vinten-Johansen J, Santamore WP, Case LD, Little WC. Mechanism of reduced cardiac output during positive end-expiratory pressure in the dog. Am Rev Respir Dis 1989; 140: 1257-1264.

58. Tucker HJ, Murray JF. Effects of end-expiratory pressure on organ blood flow in normal and diseased dogs. J Appl Physiol 1973; 34: 573-577.

59. Fessler HE, Brower RG, Wise RA, Permutt S. Effects of positive end-expiratory pressure on the canine venous return curve. Am Rev Respir Dis 1992; 146: 4-10.

60. Nanas S, Magder S. Adaptations of the peripheral circulation to PEEP. Am Rev Respir Dis 1992; 146: 688693.

61. Beloucef S, Bizot J, Leenhardt A, Payen D. PEEP increases mean systemic pressure in humans. Am J Respir Crit Care Med 1995; 151(4), 2: A708.

62. Fessler H, Brower RG, Wise RA, Permutt S. Effects of positive end-expiratory pressure on the gradient for venous return. Am Rev Respir Dis 1991; 143: 19-24.

63. Peters J, Hecker B, Neuser D, Schaden W. Regional blood volume distribution during positive and negative airway pressure breathing in supine humans. J Appl Physiol 1993; 75: 1740-1747.

64. Fessler HE, Brower RG, Shapiro EP, Permutt S. Effects of PEEP and body position on the pressure in the thoracic great veins. Am Rev Respir Dis 1993; 148: 16571664.

65. Nakhjavan FK, Palmer W, McGregor M. Influence of respiration on venous return in pulmonary emphysema. Circulation 1966; 33: 8-16.

66. Mathru M, Tadikonda LKR, El-Etr A, Pifarre R. Hemodynamic response to changes in ventilatory patterns in patients with normal and poor left ventricular reserve. Crit Care Med 1982; 10: 423-426.
67. Fessler HE, Brower RG, Wise R, Permutt S. Positive pleural pressure decreases coronary perfusion. Am J Physiol 1990; 258: H814-H820.

68. Tittley JG, Fremes SE, Weisel RD, et al. Hemodynamic and myocardial metabolic consequences of PEEP. Chest 1985; 88: 496-502.

69. Jacobs HK, Venus B. Left ventricular regional myocardial blood flows during controlled positive pressure ventilation and positive end-expiratory pressure in dogs. Crit Care Med 1983; 11: 872-875.

70. Bradley TD, Holloway RM, McLaughlin PR, Ross BL, Walters J, Liu PP. Cardiac output response to continuous positive airway pressure in congestive heart failure. Am Rev Respir Dis 1992; 145: 377-382.

71. Naughton MT, Liu PP, Benard DC, Goldstein RS, Bradley TD. Treatment of congestive heart failure and CheyneStokes respiration during sleep by continuous positive airway pressure. Am J Respir Crit Care Med 1995; 151: 92-97.

72. Genovese J, Huberfeld S, Tarasiuk A, Moskowitz M, Scharf SM. Effects of CPAP on cardiac output in pigs with pacing-induced congestive heart failure. Am J Respir Crit Care Med 1995; 152: 1847-1853.

73. Bersten AD, Holt AW, Vedig AE, Skowronski GA, Baggoley CJ. Treatment of severe cardiogenic pulmonary edema with continuous positive airway pressure delivered by face mask. $N$ Engl J Med 1991; 325: $1825-1830$.

74. Lin M, Yang Y, Chiang H, Chiang M, Chiang BN, Cheitlin MD. Reappraisal of continuous positive airway pressure therapy in acute cardiogenic pulmonary edema. Chest 1995; 107: 1379-1386.

75. Venus B, Cohen LE, Smith RA. Hemodynamics and intrathoracic pressure transmission during controlled mechanical ventilation and positive end-expiratory pressure in normal and low compliant lungs. Crit Care Med 1988; 16: 686-690.

76. Lemaire F, Teboul J, Cinotti L, et al. Acute left ventricular dysfunction during unsuccessful weaning from mechanical ventilation. Anesthesiology 1988; 69: 171-179.

77. Manthous CA, Hall JB, Kushner R, Schmidt GA, Russo G, Wood LDH. The effect of mechanical ventilation on oxygen consumption in critically ill patients. Am J Respir Crit Care Med 1995; 151: 210-214.

78. Kemper M, Weissman C, Askanazi J, Hyman AI, Kinney JM. Metabolic and respiratory changes during weaning from mechanical ventilation. Chest 1987; 92: 979983.

79. Annat GJ, Viale JP, Dereymez CP, Bouffard YM, Delafosse BX, Motin JP. Oxygen cost of breathing and diaphragmatic pressure-time index. Chest 1990; 98: 411-414.

80. Aubier M, Trippenbach T, Roussos C. Respiratory muscle fatigue during cardiogenic shock. J Appl Physiol: Respirat Environ Exercise Physiol 1981; 51(2): 499-508.

81. Aubier M, Viires N, Syllie G, Mozes R, Roussos C. Respiratory muscle contribution to lactic acidosis in low cardiac output. Am Rev Respir Dis 1982; 126: 648-652.

82. Supinski GS, Dimarco AF, Altose MD. Effect of diaphragmatic contraction on intramuscular pressure and vascular impedance. J Appl Physiol 1990; 68: 1486-1493.

83. Ward ME, Magder SA, Hussain SNA. Oxygen delivery-independent effect of blood flow on diaphragm fatigue. Am Rev Respir Dis 1992; 145: 1058-1063.

84. Kawagoe Y, Permutt S, Fessler HE. Hyperinflation with intrinsic PEEP and respiratory muscle blood flow. $J$ Appl Physiol 1994; 77(5): 2440-2448.

85. Criley JM, Blaufuss AH, Kissel GL. Cough induced 
cardiac compression. J Am Med Assoc 1976; 236: $1246-1250$

86. Kouwenhoven WB, Jude JR, Knickerbocker GG. Closedchest cardiac massage. J Am Med Assoc 1960; 173 . 94-97.

87. Chandra N, Weisfeldt ML, Tsitlik J, et al. Augmentation of carotid flow during cardiopulmonary resuscitation by ventilation at high airway pressure simultaneous with chest compression. Am J Cardiol 1981; 48: 1053-1063.

88. Rudikoff MT, Maughan WL, Effron M, Freund P, Weisfeldt ML. Mechanisms of blood flow during cardiopulmonary resuscitation. Circulation 1980; 61: 345-352.

89. Halperin HR, Guerci AD, Chandra N, et al. Vest inflation without simultaneous ventilation during cardiac arrest in dogs: improved survival from prolonged cardiopulmonary resuscitation. Circulation 1986; 74: 1407-1415.

90. Halperin HR, Tsitlik JE, Gelfand M, et al. A preliminary study of cardiopulmonary resuscitation by circumferential compression of the chest with use of a pneumatic vest. N Engl J Med 1993; 329: 762-768.

91. Niemann JT, Rosborough JP, Hausknecht M, Garner D, Criley JM. Pressure-synchronized cineangiography during experimental cardiopulmonary resuscitation. Circulation 1981; 64: 985-991.

92. Werner JA, Greene HL, Janko CL, et al. Visualization of cardiac valve motion in man during external chest compression using two-dimensional echocardiography. Circulation 1981; 63: 1417-1421.

93. Halperin HR, Tsitlik JE, Guerci, AD, et al. Determinants of blood flow to vital organs during cardiopulmonary resuscitation in dogs. Circulation 1986; 73: 539-550.

94. Maier GW, Tyson GS, Olsen CO, et al. The physiology of external cardiac massage: high-impulse cardiopulmonary resuscitation. Circulation 1984; 70: 86-101.

95. Porter TR, Ornato JP, Guard CS, Roy VG, Burns CA, Nixon JV. Transesophageal echocardiography to assess mitral valve function and flow during cardiopulmonary resuscitation. Am J Cardiol 1992; 70: 1056-1060.

96. Feneley MP, Maier GW, Kern KB, et al. Influence of compression rate on initial success of resuscitation and 24 hour survival after prolonged manual cardiopulmonary resuscitation in dogs. Circulation 1988; 77: 240-250.

97. Beattie C, Guerci AD, Hall T, et al. Mechanisms of blood flow during pneumatic vest cardiopulmonary resuscitation. J Appl Physiol 1991; 70: 454-465.

98. Koehler RC, Chandra N, Guerci AD, et al. Augmentation of cerebral perfusion by simultaneous chest compression and lung inflation with abdominal binding after cardiac arrest in dogs. Circulation 1983; 67: 266-275.

99. Krischer JP, Fine EG, Weisfeldt ML, Guerci AD, Nagel E, Chandra N. Comparison of prehospital conventional and simultaneous compression-ventilation cardiopulmonary resuscitation. Crit Care Med 1989; 17: 12631269.

100. Swenson RD, Weaver WD, Niskanen RA, Martin J, Dahlberg S. Hemodynamics in humans during conventional and experimental methods of cardiopulmonary resuscitation. Circulation 1988; 78: 630-639.

101. Wik L, Naess PA, Ilebekk A, Steen PA. Simultaneous active compression-decompression and abdominal binding increase carotid blood flow additively during cardiopulmonary resuscitation (CPR) in pigs. Resuscitation 1994; 28: 55-64.

102. Lurie KG, Coffeen P, Shultz J, McKnite S, Detloff B, Mulligan K. Improving active compression-decompression cardiopulmonary resuscitation with an inspiratory impedance valve. Circulation 1995; 91: 1629-1632.

103. Sack JB, Kesselbrenner MB, Bregman D. Survival from in-hospital cardiac arrest with interposed abdominal counterpulsation during cardiopulmonary resuscitation. J Am Med Assoc 1992; 267: 379-385.

104. Sack JB, Kesselbrenner MB, Jarrad A. Interposed abdominal compression-cardiopulmnary resuscitation and resuscitation outcome during asystole and electromechanical dissociation. Circulation 1992; 86: 1692-1700.

105. Voorhees WD III, Ralston SH, Babbs CF. Regional blood flow during cardiopulmonary resuscitation with abdominal counterpulsation in dogs. Am J Emerg Med 1983; 2: 123-128. 